

\section{Benefits to the United States of Increasing Global Uptake of Clean Energy Technologies}

\section{David Kline}

Prepared under Task No. DOCC.1002

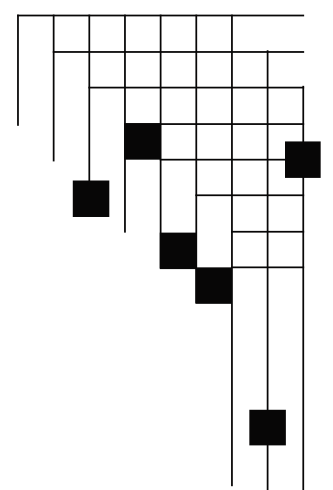




\section{NOTICE}

This report was prepared as an account of work sponsored by an agency of the United States government. Neither the United States government nor any agency thereof, nor any of their employees, makes any warranty, express or implied, or assumes any legal liability or responsibility for the accuracy, completeness, or usefulness of any information, apparatus, product, or process disclosed, or represents that its use would not infringe privately owned rights. Reference herein to any specific commercial product, process, or service by trade name, trademark, manufacturer, or otherwise does not necessarily constitute or imply its endorsement, recommendation, or favoring by the United States government or any agency thereof. The views and opinions of authors expressed herein do not necessarily state or reflect those of the United States government or any agency thereof.

Available electronically at http://www.osti.gov/bridge

Available for a processing fee to U.S. Department of Energy and its contractors, in paper, from:

U.S. Department of Energy

Office of Scientific and Technical Information

P.O. Box 62

Oak Ridge, TN 37831-0062

phone: 865.576 .8401

fax: 865.576 .5728

email: mailto:reports@adonis.osti.gov

Available for sale to the public, in paper, from:

U.S. Department of Commerce

National Technical Information Service

5285 Port Royal Road

Springfield, VA 22161

phone: 800.553.6847

fax: 703.605.6900

email: orders@ntis.fedworld.gov

online ordering: http://www.ntis.gov/ordering.htm 


\section{Acknowledgments}

A number of people contributed to the development of this paper. Thanks to Rachel Gelman and Sarah Busche, National Renewable Energy Laboratory (NREL), for research assistance in data collection and literature review. Walter Short, David Hurlbut, and Toby Couture, NREL; Tom Lyon, University of Michigan; and Keith Maskus, University of Colorado, provided useful comments on earlier drafts. I owe a particularly large debt to Jaquelin Cochran at NREL for very thoughtful discussions of the approach and for careful proofing of the algebra. Any errors or omissions in this paper remain my own responsibility. 


\section{Table of Contents}

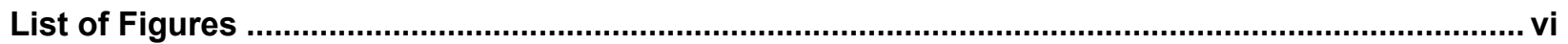

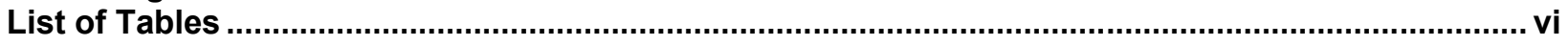

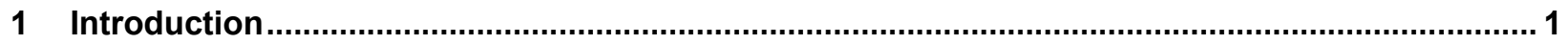

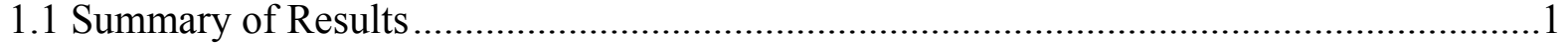

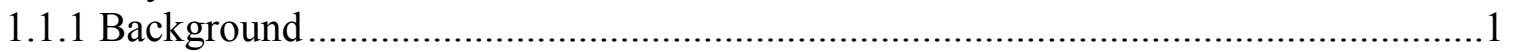

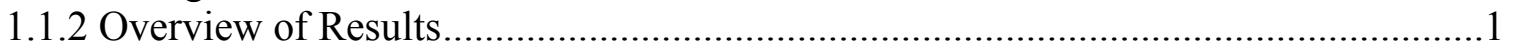

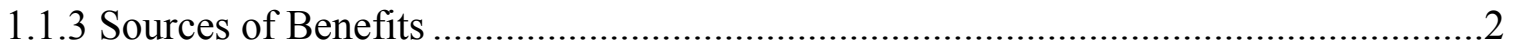

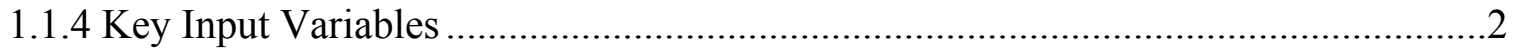

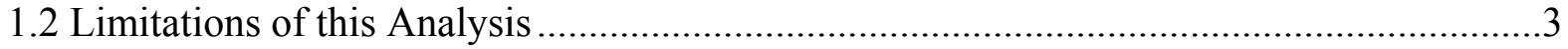

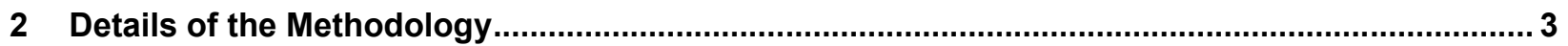

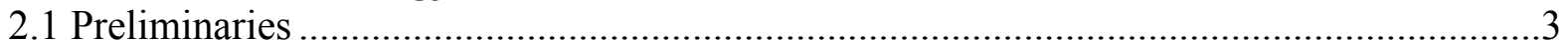

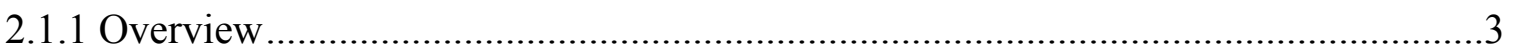

2.1.2 Naming Conventions for Variables ................................................................4

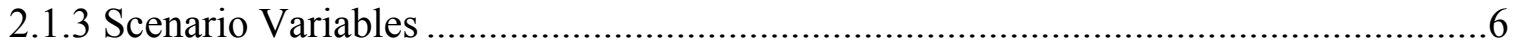

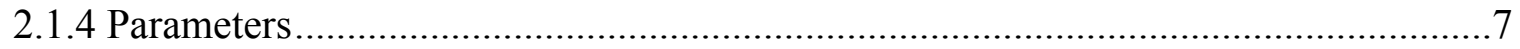

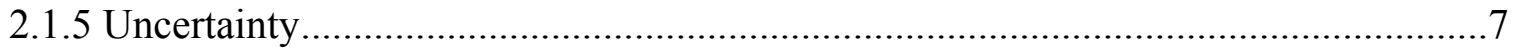

2.2 Benefits Arising from Clean Energy Markets .........................................................

2.2.1 Impacts of International Initiatives on CET Markets .......................................

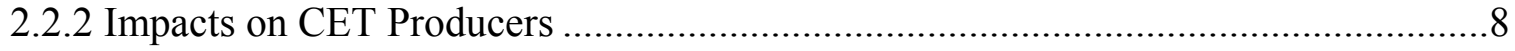

2.2.3 Impacts of Clean Energy Markets on U.S. Consumers .......................................10

2.2.4 Impact of Increased CET Sales on Balance of Payments ......................................11

2.3 Impacts on World Oil Markets ..................................................................................11

2.3.1 Impacts of Reduced Oil Price on Domestic Producers .........................................11

2.3.2 Impacts of Lower Oil Prices on U.S. Oil Consumers ............................................13

2.3.3 Impact of Reduced Oil Imports on Balance of Trade ...............................................13

2.4 Economic Benefits of Improved Trade Balance ............................................................. 14

2.4.1 Change in Import Quantity and Price as a Function of Change in the Exchange

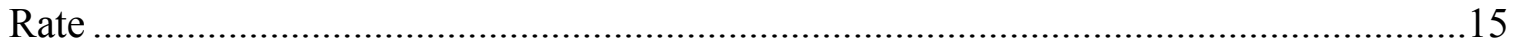

2.4.2 Change in Export Quantity and Price as a Function of Change in the Exchange

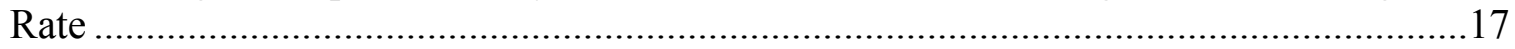

2.4.3 Induced Change in Exchange Rate ..................................................................... 19

2.4.4 Benefits of Exchange Rate Changes to Consumers ................................................19

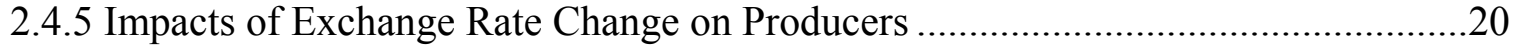

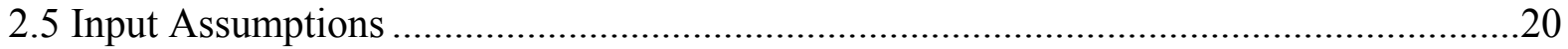

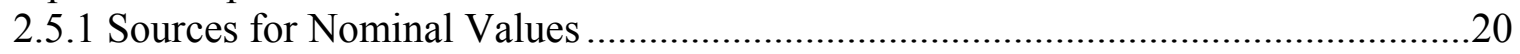

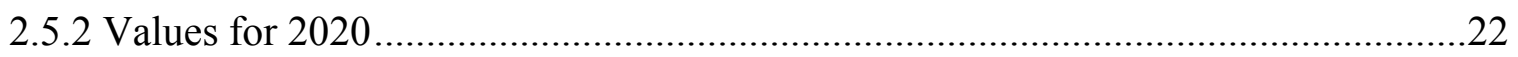

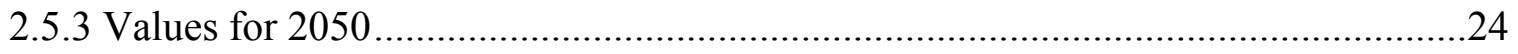


2.6 Estimating Probability Distributions for Output Variables ......................................26

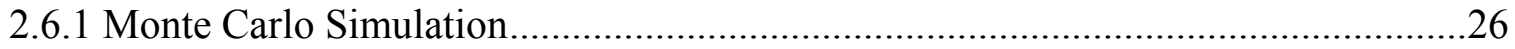

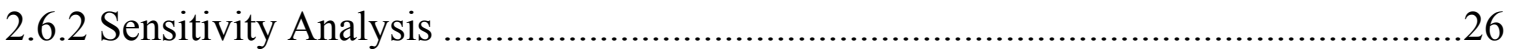

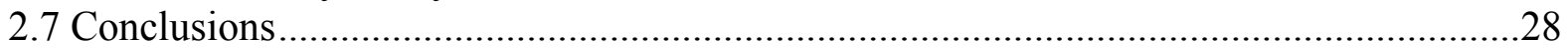

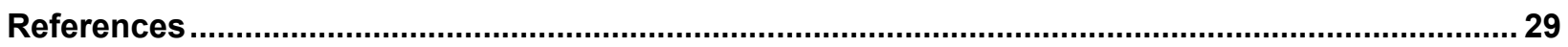




\section{List of Figures}

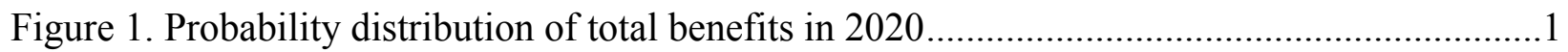

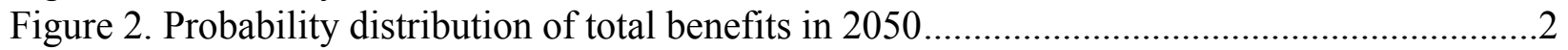

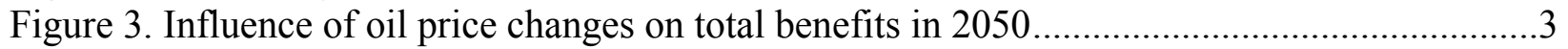

Figure 4. Change in producer surplus in the market for U.S. clean energy exports .....................8

Figure 5. Change in consumer surplus in the market for U.S. clean energy exports....................10

Figure 6. Change in U.S. oil producer surplus............................................................ 11

Figure 7. Change in consumer surplus in the U.S. oil market ..............................................13

Figure 8. Effect of exchange rate change on supply and U.S. demand for imports ....................15

Figure 9. Effects of the change in the exchange rate on U.S. exports .................................... 17

\section{List of Tables}

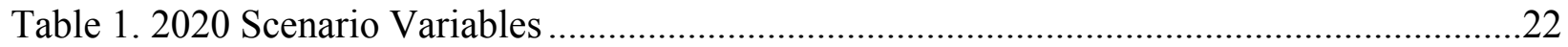

Table 2. 2020 Economic Parameters ..................................................................................23

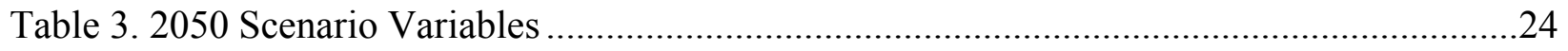

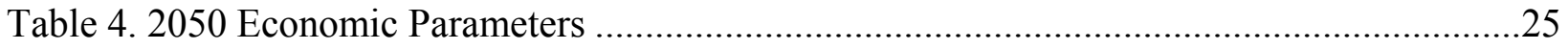

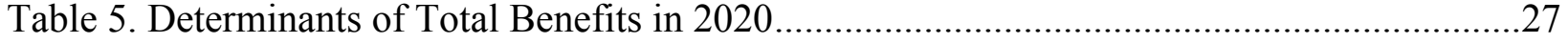

Table 6. Determinants of Total Benefits in 2050 ....................................................................27 


\section{Introduction}

\subsection{Summary of Results}

\subsubsection{Background}

The paper "Opportunities for High Impact United States Government International Renewable Energy and Energy Efficiency Initiatives" (NREL 2008) describes an opportunity for the United States to take leadership in efforts to transform the global energy system toward clean energy technologies (CET). An accompanying analysis provides estimates of the economic benefits to the United States of such a global transformation on the order of several hundred billion dollars per year by 2050. The current paper describes the methods and assumptions used in developing those benefit estimates. It begins with a summary of the results of the analysis based on an updated and refined model completed since the publication of the report mentioned above ${ }^{1}$.

\subsubsection{Overview of Results}

An effective international effort to speed the uptake of clean energy technology would have significant benefits to the United States. In 2020, estimated benefits are on the order of $\$ 40$ billion per year, and in 2050 , benefits range around $\$ 260$ billion per year. Because the results depend on a number of uncertain variables, the analysis explicitly incorporated uncertainty, resulting in estimates of the benefits and their key components. Figures 1 and 2 illustrate the range of total benefits estimated for 2020 and 2050, respectively.

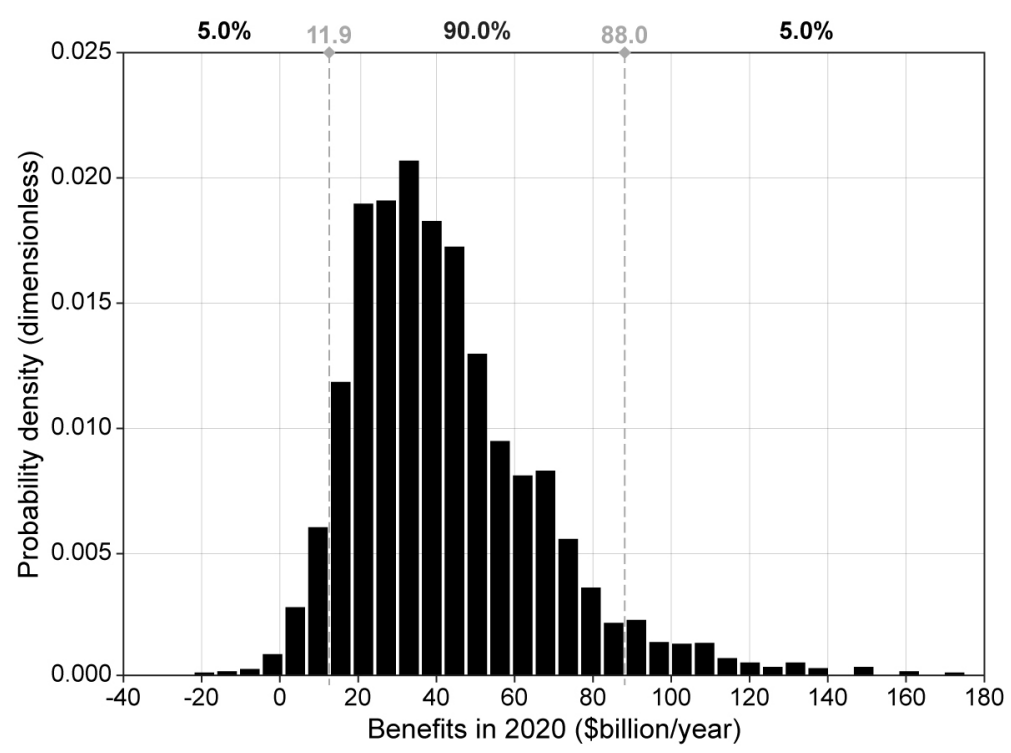

Figure 1. Probability distribution of total benefits in 2020

\footnotetext{
${ }^{1}$ The results shown here show slightly smaller benefits than those presented in NREL et al. (2008), but the policy implications remain the same.
} 


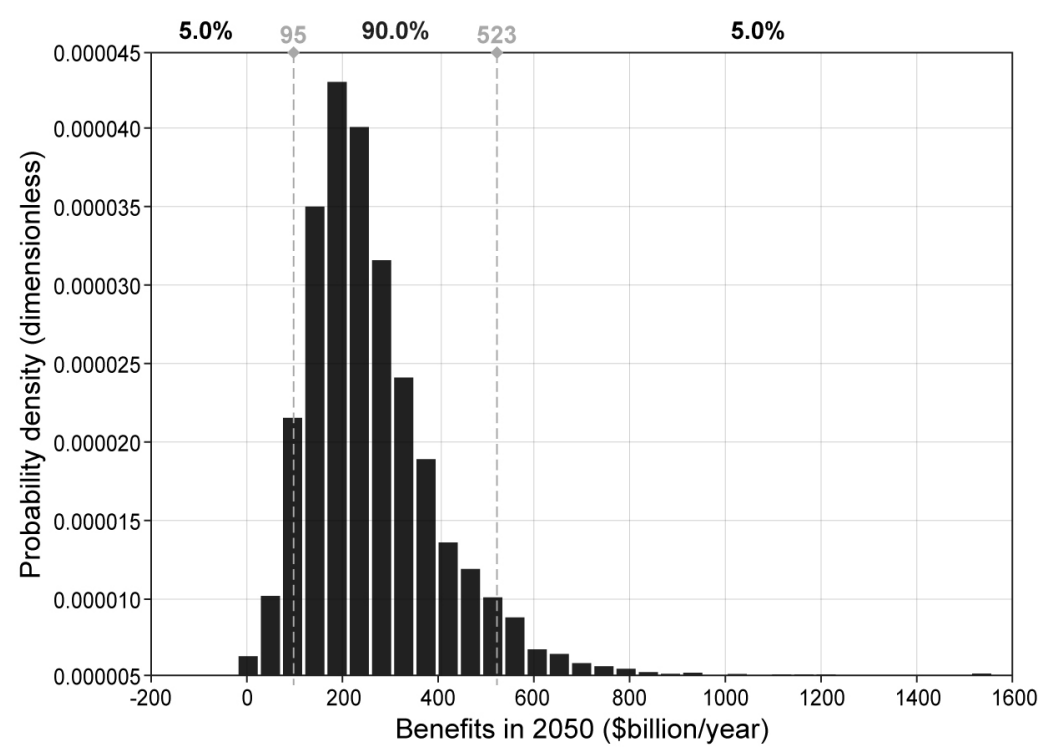

Figure 2. Probability distribution of total benefits in $\mathbf{2 0 5 0}$

\subsubsection{Sources of Benefits}

As described in more detail in Section 2, the analysis considers three sources of benefits to the U.S. economy of enhanced global clean energy use. In order of importance, the sources are reduced oil prices that result from reduced global oil demand, increased U.S. exports of CET, and improved terms of trade that result from those two impacts.

The oil market impacts tend to dominate the total benefits, contributing about $80 \%$ of the total in 2020 and $66 \%$ in 2050 . Benefits of increased clean energy exports come to about $20 \%$ of the total in 2020 and $26 \%$ of the total in 2050 . Terms of trade benefits are near zero in 2020 but grow to about $7 \%$ of the total in 2050 .

\subsubsection{Key Input Variables}

The components described above are determined by a number of input variables. In this model, the most important determinant of total benefits is the change in world oil price, and the next most important determinant is the cost of U.S. oil imports, which is a scenario variable. In 2050, U.S. oil producer revenue and some of the economic parameters that influence the value of the U.S. dollar are also important. Figure 3 illustrates the strong influence of the oil price change on total benefits in 2050 . 


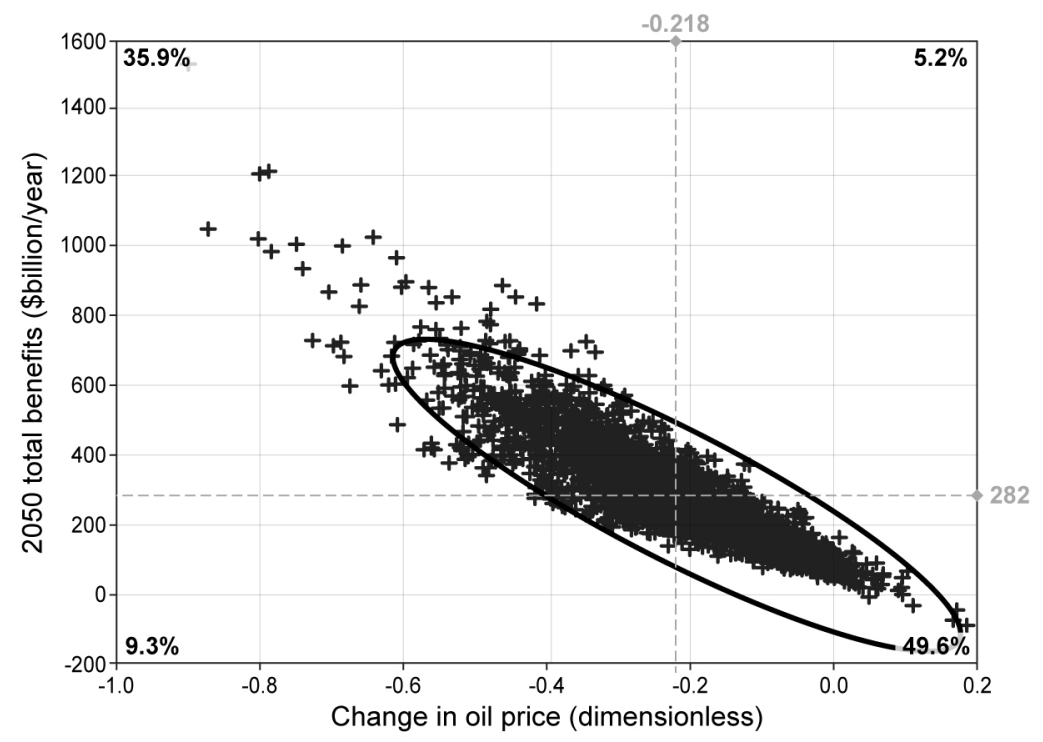

Figure 3. Influence of oil price changes on total benefits in $\mathbf{2 0 5 0}$

Section 2.5 includes further discussion of the sensitivities of the results to key input variables.

\subsection{Limitations of this Analysis}

There are two key limitations to this analysis. The first is the wide uncertainty surrounding the input variables. Those parameters include projections of market sizes and other macroeconomic variables and behavioral parameters such as demand and supply elasticities. This relatively simple model relies on a fairly large number of assumptions, as discussed below under "Scenario Variables" and "Parameters."

The second limitation is that this analysis is conducted in a partial equilibrium framework. It does include estimates for the impacts of enhanced global clean energy technology use on domestic oil producers, which are likely to be the most important adverse effects. However, a number of other sectors are not included; perhaps most importantly, intermediate energy goods such as power plant manufacturers and their supply chains were excluded. A useful extension of this work would be to recast it in a computable general equilibrium setting where all economic sectors could be examined.

\section{Details of the Methodology}

\subsection{Preliminaries}

\subsubsection{Overview}

The net benefit model used to estimate benefits considers three sources of economic impacts to U.S. producers and consumers: reduced global oil demand, expanded global clean energy markets, and the improved balance of payments that flow from the first two impacts. In this 
simplified representation, $\mathrm{CETs}^{2}$ are modeled as one aggregate good with a single price. Similarly, "oil" is treated as a single good.

Economic benefits are measured as changes in consumer and producer surplus between a postulated business-as-usual scenario and the successful CET initiative scenario. Those scenarios are described in Section 2.5.

\subsubsection{Naming Conventions for Variables}

This paper uses the following naming conventions for variables:

\subsubsection{Quantity and prices in U.S. goods markets}

$P$ and $Q$ are price and quantity variables, respectively. $P$ and $Q$ refer to market clearing values.

Subscripts indicate which goods the prices and quantities refer to.

Subscript $L$ : Oil. $P_{L}$ represents the price of oil and similarly for other variables.

A distinction is made between U.S. and world quantities of oil ${ }^{3}$.

Subscript $L W$ : World oil. $Q_{L W}$ represents world oil quantity

Subscript $L U$ : U.S. oil. $Q_{L U}$ represents U.S. oil quantity.

$S_{L U}$ denotes quantity of oil supplied by U.S. producers.

\subsubsection{Imports and Exports}

The discussion uses the following import and export variables:

$Q_{X T}$ : Quantity of total U.S. exports in physical units.

$Q_{I T}$ : Quantity of total U.S. imports in physical units.

$Q_{X R}$ : Quantity of U.S. clean energy exports in physical units. ( $R$ is a mnemonic for "renewable energy and energy efficiency.")

$Q_{I L}$ : Quantity of U.S. oil imports in physical units.

Prices of imports and exports are sometimes expressed in dollars and sometimes in terms of a basket of foreign currencies denoted by a second subscript $\$$ or $F$. For example, the price of U.S. imports in foreign currency and dollars is written as $P_{I F}$ and $P_{I \$}$, respectively.

Exchange rates give the conversion rate between prices in dollars and foreign currency. In most cases, the exchange used is $E$, the value of the U.S. dollar expressed in terms of a basket of foreign currencies $(F)$. In price-quantity graphs, the price axis will be labeled " $E(F / \$)$," where " $F / \$$ " indicates the units mentioned above. So we can write, for example, $P_{I F}=E P_{I \$}$.

\footnotetext{
2 The model is not intended to include nuclear energy technologies as part of "clean energy," and the input assumptions were derived by looking at statistics that do not include nuclear.

${ }^{3} L$ is used as a subscript for oil rather than $O$, which could be mistaken for a zero implying an initial value.
} 
In some cases, the exposition will be clearer if the exchange rate is expressed as the value of the basket of foreign currencies in U.S. dollars, $G=1 / E$. That axis will be labeled " $G(\$ / F)$."

The presentation also relies on the corresponding dollar values of import and export quantities:

$X_{T}$ : Value of total U.S. exports, considered as a single aggregate good.

$I_{T}$ : Value of total U.S. imports, considered as a single aggregate good.

$I_{L}$ : Value of U.S. oil imports.

$X_{R}$ : Value of U.S. CET exports.

$X$ and $I$ are in units of dollar values, so that, for example, $X_{T}=P_{X \$} Q_{X T}$

\subsubsection{Producer and Consumer Surplus}

$C S$ : Consumer surplus in the market indicated by the subscript. $C S_{L}$ represents consumer surplus in the market for oil products and similarly for other subscripts.

PS: Producer surplus in the market indicated by the subscript.

\subsubsection{Elasticities}

$\varepsilon$ : Price elasticity of demand for the good. For example, $\varepsilon_{L}$ represents the price elasticity of U.S. demand for oil.

$\beta$ : Price elasticity of supply for the good indicated by the subscript.

\subsubsection{Difference Operators}

This analysis derives estimates of the change in relevant metrics (e.g., CS and PS) between a baseline (ex ante) value and the value in a case including the program or initiative under consideration (the "ex post" value).

Baseline values for variables are indicated by a "hat." For example, $\hat{P}_{L}$ is the baseline world oil price.

The operator $\Delta(\cdot)$ gives the change in the variable between the ex post and ex ante values. For example $\Delta P_{L}$ is the difference between ex post and ex ante world oil price. 
More frequently, the changes are expressed in proportional terms, denoted by the difference operator $\delta(\cdot)$. For example, $\delta P L$ is the proportional change in world oil price, or

$$
\delta P_{L}=\frac{\Delta P_{L}}{\hat{P}_{L}}
$$

\subsubsection{Scenario Variables}

As described in more detail in Section 2.5, the independent variables for our model are derived from scenarios that describe a global initiative to significantly reduce greenhouse gas (GHG) emissions by the year 2050. Accordingly, these variables are often referred to collectively as "scenario variables." The nominal values of the scenario variables are chosen as representatives of the recently published estimates of CET penetrations needed to support $50 \%-80 \%$ reductions in GHG emissions by 2050. The scenario variables are the following:

$\delta Q_{L} \quad$ Proportional change in world oil consumption.

$\delta P_{R} \quad$ Proportional change in the world price of the aggregate good CET.

$\delta \mathrm{P}_{L} \quad$ Proportional change in world oil price ${ }^{4}$.

$\hat{P}_{L} \hat{Q}_{L U} \quad$ Baseline U.S. oil import bill ${ }^{5}$.

$\frac{\hat{Q}_{I L}}{\hat{Q}_{L U}}$

Ratio of U.S. oil imports to U.S. oil consumption (“dependence ratio") ${ }^{6}$.

$\delta X_{R} \quad$ Proportional change in dollar value of U.S. CET exports.

$\hat{P}_{R} \hat{Q}_{R U} \quad$ Baseline U.S. expenditures on CET.

$\hat{P}_{R} \hat{Q}_{X R} \quad$ Baseline value of U.S. CET exports.

$\hat{I}_{T}+\hat{X}_{T} \quad$ Baseline dollar value of U.S. total trade.

$D=\frac{\hat{I}_{T}-\hat{X}_{T}}{\hat{I}_{T}+\hat{X}_{T}} \quad$ Trade balance as a fraction of total trade.

\footnotetext{
${ }^{4} \delta P_{L}$ is a function of $\delta Q_{L}$ as described in Eq. [5]. It is included as a separate scenario variable because it is modeled as random, as described in Section 2.5. See note to Table 1 .

${ }^{5}$ For U.S. oil imports, CET expenditures, and CET exports, prices and quantities need not be forecast separately because the model only requires their product. Results are expressed in terms of those products and the proportional changes in prices and quantities. That approach is particularly important for the aggregate good CET because it avoids the problem of constructing a price index scheme.

${ }^{6}$ In this model, neither the physical quantity of oil consumed in the U.S. nor the price of oil are used explicitly. The model relies only on the value of U.S. oil imports, which is the product of the two. In order to estimate the impact of oil price changes on imports, the model also uses an exogenous value for the dependence ratio defined here.
} 
$F_{I}$ Value of U.S. imports as a fraction of global trade in the import good.

$F_{X}$ Value of U.S. exports as a fraction of global exports.

\subsubsection{Parameters}

In addition to the scenario variables, the model uses economic parameters that describe producer and consumer behavior for the relevant markets. Parameters include price elasticities of supply and demand.

$\varepsilon$ represents price elasticity of demand, qualified by the following subscripts:

$\varepsilon_{R U} \quad$ Price elasticity of U.S. demand for CETs.

$\varepsilon_{L U} \quad$ Price elasticity of U.S. demand for oil.

$\varepsilon_{I} \quad$ Price elasticity of U.S. demand for imports.

$\varepsilon_{X} \quad$ Price elasticity of demand overseas for U.S. exports.

$\beta$ represents price elasticity of supply, qualified by the following subscripts:

$\beta_{L U} \quad$ Price elasticity of U.S. oil supply.

$\beta_{L W} \quad$ Price elasticity of world oil supply.

$\beta_{R} \quad$ Price elasticity of U.S. CET supply.

$\beta_{X} \quad$ Price elasticity of total U.S. exports supply.

$\beta_{I} \quad$ Price elasticity of total U.S. imports supply.

\subsubsection{Uncertainty}

The scenario variables and parameters can only be very imperfectly estimated. One source of uncertainty comes from forecasts of variables such as U.S. expenditures on oil imports. Other uncertain inputs are associated with behavioral parameters, e.g., the elasticity of demand for U.S. oil imports. To account for these uncertainties, the analysis defines probability distributions for both scenario variables and parameters. Those distributions are then used to estimate probability distributions for the outputs using Monte Carlo simulation. The discussion that follows first describes the deterministic model and then describes the input parameters and their probability distributions in Section 2.5. 


\subsection{Benefits Arising from Clean Energy Markets}

\subsubsection{Impacts of International Initiatives on CET Markets}

U.S.-led CET efforts are expected to have two impacts that will benefit the U.S. economy. First and probably most importantly, those efforts will increase the global demand for CETs by addressing market barriers and providing technical assistance in the design of CET policies and programs. U.S. programs will also include trade-related efforts that will enable U.S. producers to gain market share. Increased CET exports from the United States are one of the two primary drivers of U.S. economic benefits.

The second impact of CET initiatives in this market will be on CET prices. The direction of this effect is equivocal. Increased demand will increase market clearing prices if the supply curve does not change. However, since U.S. CET industries are expected to be involved in the overall international efforts, their supply capability is expected to increase in response to their increased export opportunities.

\subsubsection{Impacts on CET Producers}

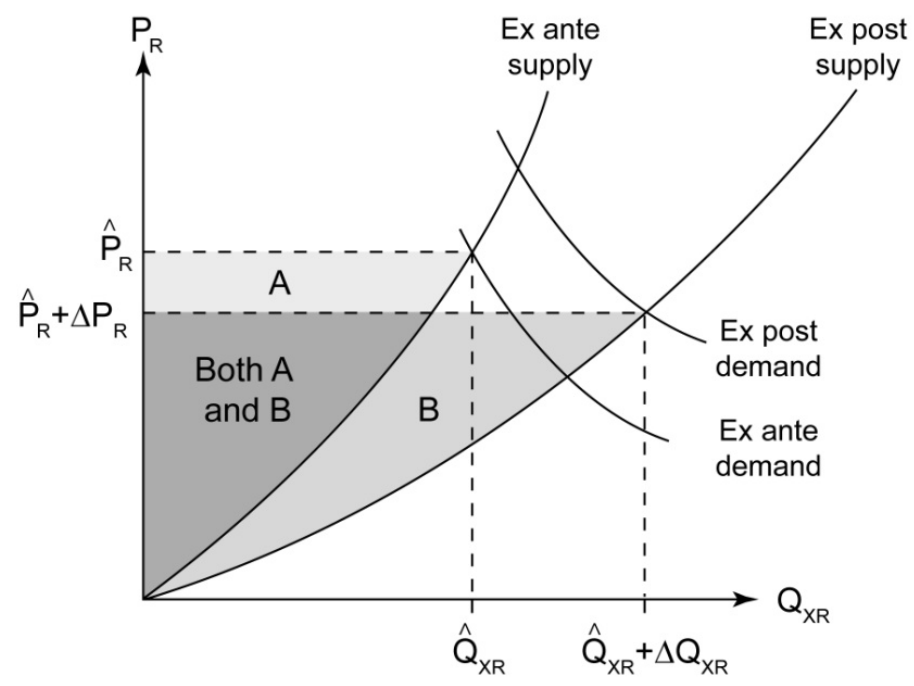

Figure 4. Change in producer surplus in the market for U.S. clean energy exports

We use the change in producer surplus as the measure of impacts on U.S. CET producers. Figure 4 illustrates the ex ante and ex post producer surplus. Next, we describe the difference between ex post and ex ante producer surplus.

CET export revenue $\hat{X}_{R}=\hat{P}_{R} \widehat{Q}_{X R}$ and the proportional changes $\delta P_{R}$ and $\delta X_{R}$ are scenario variables. We would expect dramatically larger world demand to increase overseas demand for U.S. clean energy exports, increasing $Q_{X R}$. The sign of $\delta P_{R}$ depends on how U.S. industry responds to the increased demand. For small increases in $Q_{R}$, it may be reasonable to assume that U.S. industry expands enough to keep $P_{R}$ approximately constant. If the program under consideration includes a large component of cooperative research and development, $P_{R}$ could 
decrease. If demand increases faster than the industry expands, prices could increase. As described in Section 2.5, the analysis considers a range of values for $\delta P_{R}$.

The change in producer surplus is given by the difference between Areas A and B in Figure 4. Area A is the producer surplus when market clearing values are given by $\hat{P}_{R}$ and $\hat{Q}_{X R}$. By assumption, U.S. supply of CET is represented by a constant elasticity supply curve, which is given by

$Q_{X R}(p)=\hat{Q}_{X R}\left(\frac{p}{\hat{P}_{R}}\right)^{\beta_{R}}$

The running variable $p$ represents clean energy price. Area A is given by

$A=\left(\frac{\hat{Q}_{X R}}{\hat{P}_{R}^{\beta_{R}}}\right) \int_{0}^{\hat{P}_{R}} p^{\beta_{R}} d p$

which on carrying out the integration and simplifying gives

$A=\frac{\hat{P}_{R} \hat{Q}_{X R}}{\beta_{R}+1}$

Similarly, Area B is given by

$B=\frac{\left(\hat{P}_{R}+\Delta P_{R}\right)\left(\hat{Q}_{X R}+\Delta Q_{X R}\right)}{\beta_{R}+1}$

The difference between the two is then

$\Delta P S_{R}=\frac{\hat{P}_{R} \Delta Q_{X R}+\Delta P_{R} \hat{Q}_{X R}+\Delta P_{R} \Delta Q_{X R}}{\beta_{R}+1}$

Equation [1] expresses $\triangle P S_{R}$ in terms of scenario variables and parameters and is used in the benefits calculations. Note that the numerator is simply the change in the value of U.S. CET exports, $\Delta\left(P_{R} Q_{R}\right)$. 


\subsubsection{Impacts of Clean Energy Markets on U.S. Consumers}

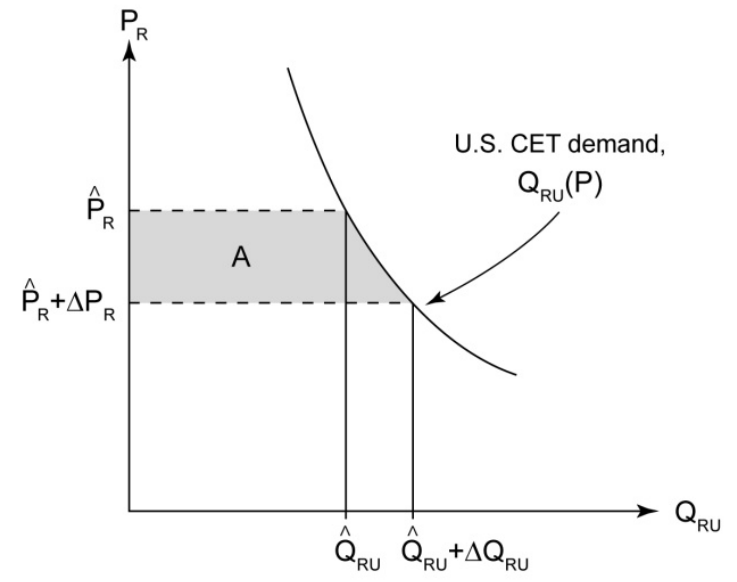

Figure 5. Change in consumer surplus in the market for U.S. clean energy exports

Since we are trying to isolate the impacts of U.S. leadership internationally, we do not include any impacts of that program on the domestic demand for CET. Accordingly, the estimated impact on U.S. CET consumers depends only on the change in price and on baseline CET expenditures. The consumer surplus impact is illustrated in Figure 5 and can be found by integrating under the U.S. CET demand curve $Q_{R U}(p)$.

$$
\Delta C S_{R U}=\int_{\hat{P}_{R}+\Delta P}^{\hat{P}_{R}} Q_{R U}(p) d p
$$

The assumed constant elasticity demand curve can be written

$Q_{R U}(p)=\hat{Q}_{R U}\left(\frac{p}{\hat{P}_{R}}\right)^{\varepsilon_{R U}}$

which substituted into Eq. [2] gives

$$
\Delta C S_{R U}=\left(\frac{\hat{Q}_{R U}}{\hat{P}_{R}^{\varepsilon_{R U}}}\right) \int_{\hat{P}_{R}+\Delta P_{R}}^{\hat{P}_{R}} p^{\varepsilon_{R U}} d p
$$

Carrying out the integration gives

$$
\Delta C S_{R U}=\left(\frac{\hat{Q}_{R U}}{\hat{P}_{R}^{\varepsilon_{R U}}}\right)\left[\frac{\hat{P}_{R}^{\varepsilon_{R U}+1}-\left(\hat{P}_{R}+\Delta P_{R}\right)^{\varepsilon_{R U}+1}}{\varepsilon_{R U}+1}\right]
$$


which can be simplified to

$$
\Delta C S_{R U}=\hat{P}_{R} \hat{Q}_{R U}\left[\frac{1-\left(1+\delta P_{R}\right)^{\varepsilon_{R U}+1}}{\varepsilon_{R U}+1}\right]
$$

\subsubsection{Impact of Increased CET Sales on Balance of Payments}

The balance of trade impact of the increase in CET exports can also be visualized in Figure 4. That impact is the difference between ex post and ex ante CET export revenue. Since both $\hat{X}_{T}$ and $\delta X_{R}$ are scenario variables, we can express the change in the value of exports as

$\Delta X_{R}=\hat{X}_{T} \cdot \delta X_{R}$

\subsection{Impacts on World Oil Markets}

Global cooperation on CET technologies will include fuel substitution and efficiency technologies that will reduce global oil demand. Reduced demand will tend to reduce world oil prices relative to baseline values. U.S. oil consumers will benefit. Although U.S. oil producers will see lower revenues, those losses will be more than offset by gains to consumers ${ }^{7}$.

\subsubsection{Impacts of Reduced Oil Price on Domestic Producers}

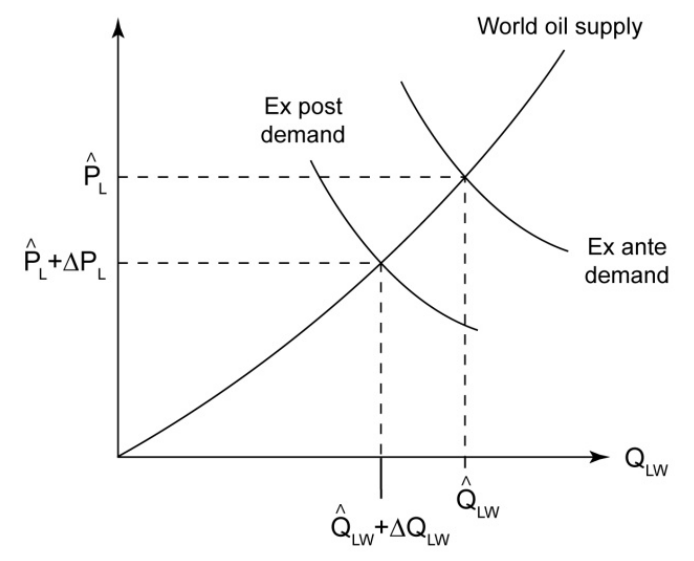

Figure 6. Change in U.S. oil producer surplus

Figure 6 illustrates the effect of reduced oil prices on domestic oil producers. To quantify those impacts, we first find the change in world oil price that results from the given change in world oil

\footnotetext{
${ }^{7}$ The impact of changes in oil demand on oil price is modeled simply using the elasticity of supply for world oil. The nominal value for world supply elasticity is +2 with a large uncertainty range as described in Section 2.5 . The nominal value is judged to be high in order to give a conservative estimate of the impact on world oil prices. (In contrast, U.S. supply is assumed to be relatively inelastic with a supply elasticity in the range of 0.3.) In general, the benefits to oil consumers will be larger than costs to domestic producers as long as oil is imported.
} 
demand $\delta Q_{L W}$. Assuming that the world supply curve has constant elasticity $\beta_{L W}$, the inverse supply curve can be written ${ }^{8}$

$P_{L}(q)=\hat{P}_{L}\left(\frac{q}{\hat{Q}_{L W}}\right)^{1 / \beta_{L W}}$

Setting $q=\hat{Q}_{L W}+\Delta Q_{L W}$ gives

$\hat{P}_{L}+\Delta P_{L}=\hat{P}_{L}\left[\frac{\hat{Q}_{L W}+\Delta Q_{L W}}{\hat{Q}_{L W}}\right]^{1 / \beta_{L W}}=\hat{P}_{L}\left(1+\delta Q_{L W}\right)^{1 / \beta_{L W}}$

Subtracting $\hat{P}_{L}$ from both sides and dividing through by $\hat{P}_{L}$ yields

$$
\delta P_{L}=\left(1+\delta Q_{L W}\right)^{1 / \beta_{L W}}-1
$$

The impact of reduced oil prices on producer surplus can be calculated by integrating under the U.S. oil supply curve,

$$
\Delta P S_{R U}=\int_{\hat{P}_{R}}^{\hat{P}_{R}+\Delta P} S_{L U}(p) d p
$$

The supply curve is assumed to have constant elasticity $\beta_{L U}$ so that

$$
S_{L U}(p)=\hat{S}_{L U}\left(\frac{p}{\hat{P}_{L}}\right)^{\beta_{L U}}
$$

Carrying out the integration and simplifying gives

$$
\Delta P S_{L}=\hat{P}_{L} \hat{Q}_{L}\left[\frac{\left(1+\delta P_{L}\right)^{\beta_{L U}+1}-1}{\beta_{L U}+1}\right]
$$

Baseline U.S. oil producer revenue, $\hat{P}_{L} \hat{Q}$, can be found from the baseline import bill and the dependence ratio, which are both scenario variables.

\footnotetext{
${ }^{8}$ The complexities of the world oil market make the concept of an "oil supply curve" a questionable concept. As explained in Section 2.5, treating the elasticity of supply as a random variable is our way of accounting for the fact that the supply-price relationship is known only imperfectly.
} 


\subsubsection{Impacts of Lower Oil Prices on U.S. Oil Consumers}

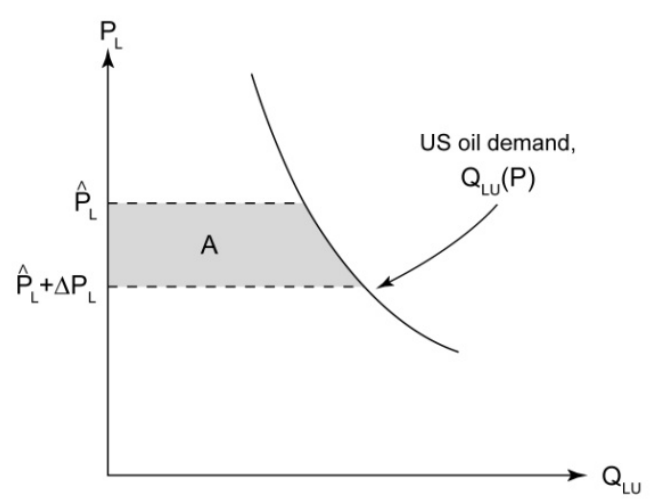

Figure 7. Change in consumer surplus in the U.S. oil market

The change in consumer surplus arising from lower oil prices is shown as Area A in Figure 7, which can be written in terms of scenario variables as

$$
\Delta C S_{L U}=\hat{P}_{L U} \hat{Q}_{L U}\left[\frac{1-\left(1+\delta P_{L}\right)^{\varepsilon_{L U}+1}}{\varepsilon_{L U}+1}\right]
$$

The derivation is exactly analogous to the one for Eq. [3].

\subsubsection{Impact of Reduced Oil Imports on Balance of Trade}

Reduced oil imports improve the balance of trade. The change can be written in terms of the initial oil import bill and the proportional changes in oil price and oil imports.

To find the change in oil imports, first write U.S. imports as the difference between domestic consumption and domestic supply:

$Q_{I L}=Q_{L U}-S_{L U}$

This implies

$\Delta Q_{I L}=\Delta Q_{L U}-\Delta S_{L U}$ 
From the respective demand and supply curves for U.S. oil, we can write

$$
\begin{aligned}
& \left.\Delta Q_{L U}=\hat{Q}_{L U} \mid\left(1+\delta P_{L}\right)^{\varepsilon_{L U}}-1\right] \text { and } \\
& \Delta S_{L U}=\hat{S}_{L U}\left[\left(1+\delta P_{L}\right)^{\beta_{L U}}-1\right]
\end{aligned}
$$

Subtracting the two previous expressions and dividing through by $\hat{Q}_{I L}$ gives

$$
\delta Q_{I L}=\frac{\hat{Q}_{L U}}{\hat{Q}_{I L}}\left[\left(1+\delta P_{L}\right)^{\varepsilon_{L U}}-1\right]-\frac{\hat{S}_{L U}}{\hat{Q}_{I L}}\left[\left(1+\delta P_{L}\right)^{\beta_{L U}}-1\right]
$$

Recall that $\hat{Q}_{I L} / \hat{Q}_{L U}$ is a scenario variable, and note that $\hat{S}_{L U} / \hat{I}_{L U}$ can be derived from it using $\hat{Q}_{L U}=\hat{S}_{L U}+\hat{Q}_{I L}$. Thus, the previous expression gives $\delta Q_{I L}$ in terms of scenario variables.

Knowing $\delta Q_{I L}$, we can write the balance change in payments induced by reduced oil imports as

$$
\Delta\left(P_{L} Q_{I L}\right) \equiv \Delta I_{L U}=\hat{P}_{L} \hat{Q}_{I L}\left(\delta P_{L}+\delta Q_{I L}+\delta P_{L} \delta Q_{I L}\right)
$$

\subsection{Economic Benefits of Improved Trade Balance}

The impact of the improved trade balance operates through the change in exchange rates. The fundamental assumption used here is that exchange rates move so as to maintain the ex ante value of the trade balance. That is, the balance of payments change induced by the exchange rate adjustment will just offset the balance of trade changes in the oil and CET markets given in Eqs. [4] and [8].

In Section 2.4.1 we solve for the change in total imports as a function of changes in the exchange rate. Section 2.4.2 repeats the process for exports. Section 2.4.3 uses those results to solve for the exchange rate that meets the balance of trade condition given in the paragraph above. The trade balance is shown as zero in Figures 8 and 9, but the model treats the trade balance as an uncertain variable with a wide range (see Section 2.5). 


\subsubsection{Change in Import Quantity and Price as a Function of Change in the Exchange Rate}

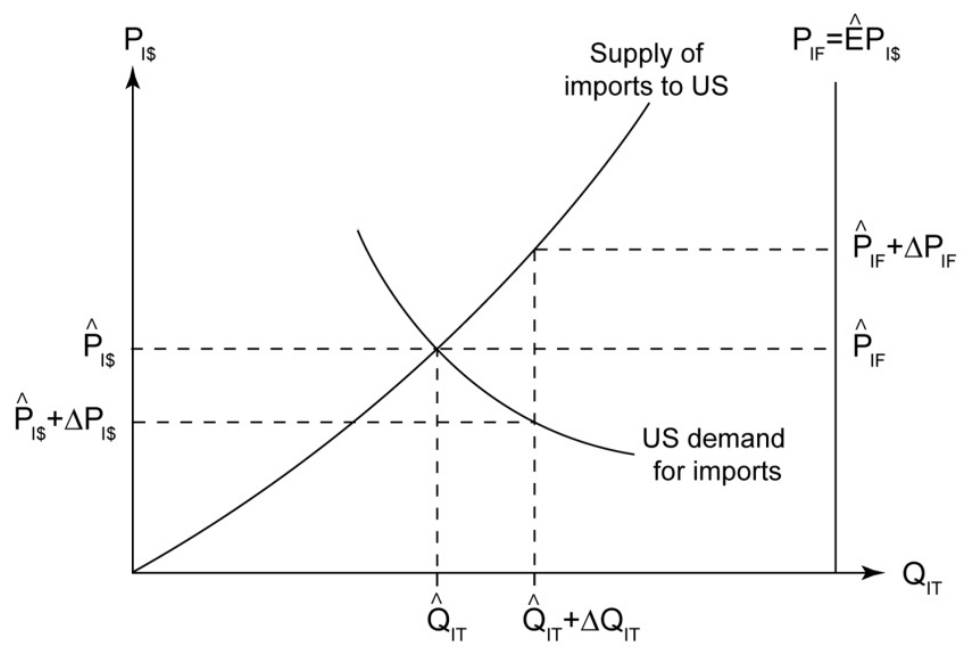

Figure 8. Effect of exchange rate change on supply and U.S. demand for imports

Figure 8 shows the supply of imports to the United States as a function of $P_{I F}$ and the demand as a function of $P_{I \$}$. A proportional change in the indirect exchange rate of $\delta E$ functions like a subsidy on imports, lowering $P_{I \$}$ and raising $P_{I F}$.

Assuming that the price of the basket of imported goods will be the same regardless of where they are purchased ("purchasing power parity," or PPP), we can write

$$
\hat{E}_{T}+\Delta E_{T}=\left[\frac{\hat{P}_{I F}+\Delta P_{I F}}{\hat{P}_{I \$}+\Delta P_{I \$}}\right]
$$

Multiplying by $\frac{\hat{P}_{I \$}}{\hat{P}_{I F}}=\frac{1}{\hat{E}}$ yields

$1+\delta E_{T}=\frac{1+\delta P_{I F}}{1+\delta P_{I \$}}$

Since the changes in prices and the exchange rates are small, ${ }^{9}$ we can use a linear approximation based on a constant elasticity demand curve to approximate the change in U.S. import quantity as

$\delta Q_{I T} \approx \varepsilon_{I} \delta P_{I \$}$

U.S. consumption of imports and the total world supply of the import good $Q_{I W}$ are related by

\footnotetext{
${ }^{9}$ Numerical experiments confirm that price and exchange rates change by at most a few percent.
} 
$\hat{Q}_{I T}=F_{I} \hat{Q}_{I W}$

To move from the ex ante to the ex post state shown in Figure 8 requires that

$\Delta Q_{I T}=\Delta Q_{I W}$

which implies that

$\delta Q_{I T}=F_{I}^{-1} \delta Q_{I W}$

The linear approximation to the world supply curve for the import good (priced in foreign currency) gives

$\delta Q_{I W}=\beta \delta P_{I F}$

Equations [10]-[12] can be combined to eliminate the quantity variables and solve for $P_{I F}$ to give

$\delta P_{I F}=F_{I} \beta_{I}^{-1} \varepsilon_{I} \delta P_{I \$}$

This equation can be combined with Eq. [9] to give

$1+\delta E_{T}=\frac{1+F_{I} \beta_{I}^{-1} \varepsilon_{I} \delta P_{I \$}}{1+\delta P_{I \$}}$

which leads to ${ }^{10}$

$1+\delta E_{T}+\delta P_{I \$}+\delta P_{I \$} \delta E_{T}=1+F_{I} \beta_{I}^{-1} \varepsilon_{I} \delta P_{I \$}$

Dropping the second order term and solving for $\delta P_{I \$}$ gives

$\delta P_{I \$}=\frac{\delta E_{T} \beta_{I}}{F_{I} \varepsilon_{I}-\beta_{I}}$

${ }^{10}$ In multiplying by the numerator, we can be confident it is nonzero. It could only become zero if $P_{I \$}$ has gone to zero, which can be ruled out. 
which can be combined with Eq. [10] to give

$$
\delta Q_{I T}=\frac{\delta E \varepsilon_{I} \beta_{I}}{F_{I} \varepsilon_{I}-\beta_{I}}
$$

Using the linear approximation

$\delta\left(P_{I \$} Q_{I T}\right) \approx \delta P_{I \$}+\delta Q_{I}$

we can add Eqs. [14] and [15] to write the change in imports, $\Delta I_{T} \equiv \Delta\left(P_{I \$} Q_{I}\right)$, as

$$
\Delta I_{T} \approx \hat{I}_{T} \delta E \frac{\beta_{I}\left(\varepsilon_{I}+1\right)}{F_{I} \varepsilon_{I}-\beta_{I}}
$$

Equation [16] gives the change in the value of imports as a function of changes in the exchange rate. Equation [14] gives the change in price as a function of the change in exchange rates.

\subsubsection{Change in Export Quantity and Price as a Function of Change in the Exchange Rate}

The derivation of the change in exports proceeds similarly to that for imports, as illustrated in Figure 9.

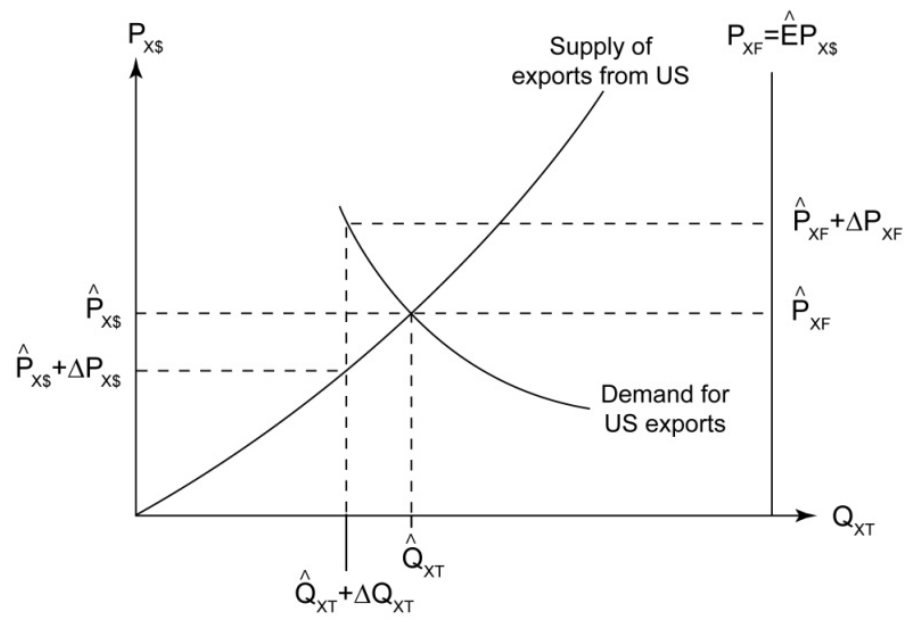

Figure 9. Effects of the change in the exchange rate on U.S. exports

As illustrated in Figure 9, the change in exchange rates functions like a tax on exports. The change in the exchange rate induces both a decrease in the overseas price $P_{F}$ and an increase in the dollar price $P_{\$}$. 
As in Section 2.4.1, PPP implies

$$
1+\delta E_{T}=\frac{1+\delta P_{X F}}{1+\delta P_{X S}}
$$

The linear approximation to the supply condition for U.S .exports is

$$
\delta Q_{X T} \approx \beta_{X} \delta P_{X \varsigma}
$$

and the demand curve gives

$$
\delta Q_{X W} \approx \varepsilon_{X} \delta P_{X F}
$$

Similarly to Eqs. [11] and [13] for imports, we have

$$
\delta Q_{X T}=F_{I}^{-1} \delta Q_{X W}
$$

and

$$
\delta P_{X F}=F_{X} \varepsilon_{X}^{-1} \delta P_{X \$}
$$

Substituting from Eq. [20] into Eq. [17], dropping second order terms and solving for $\delta P_{X S}$ gives

$$
\delta P_{X S} \approx \delta E_{T} \frac{\varepsilon_{X}}{\left(F_{X} \beta_{X}-\varepsilon_{X}\right)}
$$

which together with Eq. [18] gives

$$
\delta Q_{X T} \approx \delta E_{T} \frac{\varepsilon_{X} \beta_{X}}{\left(F_{X} \beta_{X}-\varepsilon_{X}\right)}
$$

Using the linear approximation

$$
\delta\left(P_{X \S} Q_{X T}\right) \approx \delta P_{X I \Phi}+\delta Q_{X T}
$$

we can then write

$$
\Delta X_{T} \approx \hat{X}_{T} \delta E \frac{\varepsilon_{X}\left(\beta_{X}+1\right)}{F_{X} \beta_{X}-\varepsilon_{X}}
$$




\subsubsection{Induced Change in Exchange Rate}

For compactness, rewrite [16] as

$\Delta I_{T} \approx a \hat{I}_{T} \delta E$

and $[22]$ as

$\Delta X_{T} \approx b \hat{X}_{T} \delta E$

with $a$ and $b$ having the appropriate values as given in Eqs. [14] and [17]. The equilibrium assumption is that the balance of payments change given by the difference between those two expressions just offset the balance of payments changes in the CET and oil markets, i.e., $\delta E\left(a \hat{I}_{T}-b \hat{X}_{T}\right)=\Delta X_{R}-\Delta I_{L U}$

which immediately gives the required change in exchange rate as

$\delta E=\frac{\Delta X_{R}-\Delta I_{L U}}{a \hat{I}_{T}-b \hat{X}_{T}}$

Note that in the model, $\hat{X}_{T}$ and $\hat{I}_{T}$ are computed from total trade and the trade deficit, which are scenario variables. The constants $a$ and $b$ are functions of other scenario variables.

\subsubsection{Benefits of Exchange Rate Changes to Consumers}

The derivation of the change in consumer surplus in the market for U.S. imports proceeds analogously to the derivation of Eq. [3]. We can write

$\Delta C S_{I}=\int_{\hat{P}_{I S}+\Delta P_{I S}}^{\hat{P}_{I S}} Q_{I T}(p) d p$

Representing the U.S. demand for imports with a constant elasticity demand function, we can write

$Q_{I T}(p)=\hat{Q}_{I T}\left(\frac{p}{\hat{P}_{I S}}\right)^{\varepsilon_{L U}}$

Following the steps in the derivation in Section 2.2.3 leads to the analogous result

$\Delta C S_{I}=\hat{I}_{T}\left[\frac{1-\left(1+\delta P_{I \Phi}\right)^{\varepsilon_{I}+1}}{\varepsilon_{I}+1}\right]$

$\delta P_{I \$}$ is found from $\delta E$ using Eq. [14]. 


\subsubsection{Impacts of Exchange Rate Change on Producers}

Similarly, the change in producer surplus can be found by carrying out the integration

$$
\Delta P S_{X}=\int_{\hat{P}_{X S}}^{\hat{P}_{X S}+\Delta P_{X S}} Q_{X T}(p) d p
$$

Representing exports with a constant elasticity demand function, we can write

$$
Q_{X T}(p)=\left(\frac{\hat{Q}_{X T}}{\left(\hat{P}_{X \Phi}\right)^{\beta_{X}}}\right) p^{\beta_{X}}
$$

Substituting into the expression for $\triangle P S_{X}$, carrying out the integration, and simplifying gives

$$
\Delta P S_{X}=\hat{X}_{T}\left[\frac{\left(1+\delta P_{X S}\right)^{\beta_{X}+1}-1}{\beta_{X}+1}\right]
$$

where $\delta P_{X S}$ is found from $\delta E$ using Eq. [21].

\subsection{Input Assumptions}

This section describes the way that input values were characterized in this analysis. Section 2.5.1 describes the sources for nominal parameter values for scenario variables and parameters. Sections 2.5.2 and 2.5.3 describe the probability distributions used to represent the uncertainty in the input variable estimates. Section 2.6 describes the methods used to calculate probability distributions for the dependent variables in the model.

\subsubsection{Sources for Nominal Values}

Baseline assumptions for the parameters and scenario variables used in this analysis are based on a number of published projections. The approach was to use baseline values in line with published projections and use wide uncertainty ranges as described in Sections 2.5.2 and 2.5.3.

Projections of the size of the clean energy markets are based on the "Blue Map" scenario in Energy Technology Perspectives (IEA 2008). This scenario will be referred to here as "Blue Map". U.S. clean energy businesses are assumed to capture $10 \%$ of the increase in CET expenditures implied by the Blue Map scenario. Increased U.S. imports of CET are assumed to offset half of those increased exports so that net U.S. exports amount to $5 \%$ of the increased CET market.

Oil market projections also make use of the IEA (2008) work, setting baseline assumptions figures at a $25 \%$ reduction in global oil use in 2020 and $60 \%$ reduction in 2050 . Oil price reductions are taken to be half the percentage reduction in consumption which is intended as a 
conservative estimate of a highly uncertain market response to those demand reductions ${ }^{11}$. Baseline projections of U.S. oil consumption and U.S. oil producer revenue are extrapolated from the Energy Information Administration's (EIA) Annual Energy Outlook (EIA 2008b).

Other scenario variables include baseline U.S. exports and imports. Baseline assumptions are based first on a projection of U.S. GDP, which assumes $2.4 \%$ annual growth from 2006 based on EIA projections to 2030 . Total trade (exports plus imports) is assumed to be $30 \%$ of U.S. GDP based on recent trends for that ratio according to data from the United States International Trade Commission (USITC).

Baseline renewable energy export figures were also developed from USITC (2005) data, which provided an estimate for that year. Energy efficiency markets are difficult to estimate because of their diversity and the ambiguity in their definition. Energy efficiency exports were assumed to be of the same order of magnitude as renewable energy exports. U.S. consumer investments in CET were estimated as 1\% of U.S. energy expenditures in 2020 and $2 \%$ in 2050.

In addition to these scenario variables, the analysis relies on economic parameters such as elasticities. Very little empirical data were found on which to base estimates for those values. Those values must be treated as very uncertain. Likewise, the projections of market conditions 10 and 40 years in the future are also quite uncertain.

Accordingly, we have used wide ranges for both the scenario variables and the input parameters. The remainder of Section 2.5 describes the nominal values and ranges for the input parameters. Section 2.6 describes how those ranges were used to develop ranges for the benefit estimates.

In the tables that follow, the following notation is used for probability density functions:

$T(a, b, c) \quad$ Triangular distribution with lower value $a$, maximum likelihood at $b$, and upper value $c . a \leq b \leq c$

$N(m, s) \quad$ Normal distribution with mean $m$ and standard deviation $s$

\footnotetext{
${ }^{11}$ The response of oil prices to exogenous changes in oil demand has been a subject of vigorous debate since the first oil shock of 1973, with a number of competing models of the behavior of the OPEC cartel and other players. Estimating the price response to be half the consumption change corresponds to an assumption that OPEC will respond aggressively by reducing output dramatically in response to reduced prices. This estimate was chosen in order to estimate a price reduction that would be on the low end of reasonable projections.
} 


\subsubsection{Values for 2020}

Table 1. 2020 Scenario Variables

\begin{tabular}{|c|c|c|c|c|c|}
\hline Parameter & Name & Units & $\begin{array}{l}\text { Nominal } \\
\text { Value }\end{array}$ & $\begin{array}{l}\text { Probability } \\
\text { Distribution }\end{array}$ & Sources Consulted \\
\hline Baseline U.S. oil import bill & $\hat{P}_{L} \hat{Q}_{L U}$ & $\begin{array}{l}\text { \$billion per } \\
\text { year }\end{array}$ & 125 & $T(100,125,150)$ & EIA (2008a), Reference case \\
\hline $\begin{array}{l}\text { Proportional change in U.S. clean } \\
\text { technology exports }\end{array}$ & $\delta X_{R}$ & Dimensionless & $32 \%$ & $N(32 \%, 16 \%)$ & IEA (2008) \\
\hline Base U.S. expenditures on CET & $\hat{P}_{R} \hat{Q}_{X R}$ & $\begin{array}{l}\text { \$billion per } \\
\text { year }\end{array}$ & 16 & $T(8,16,24)$ & USITC (2005) \\
\hline $\begin{array}{l}\text { Trade deficit as a fraction of total } \\
\text { trade }\end{array}$ & $D=\frac{\hat{I}_{T}-\hat{X}_{T}}{\hat{I}_{T}+\hat{X}_{T}}$ & Dimensionless & $-10 \%$ & $N(10 \%, 10 \%)$ & $\begin{array}{l}\text { Assumes gradual } \\
\text { improvement from current } \\
\text { value of }-20 \%\end{array}$ \\
\hline $\begin{array}{l}\text { Value of U.S. imports as a fraction } \\
\text { of global imports }\end{array}$ & $F_{I}$ & Dimensionless & $13 \%$ & $T(10 \%, 13 \%, 16 \%)$ & WTO (2008) \\
\hline $\begin{array}{l}\text { Value of U.S. imports as a fraction } \\
\text { of global imports }\end{array}$ & $F_{X}$ & Dimensionless & $10 \%$ & $T(8 \%, 10 \%, 12 \%)$ & WTO (2008) \\
\hline
\end{tabular}

$12 \delta P_{L}$ is calculated as a random function of its baseline value as follows. First, a baseline value is calculated from the value for $\delta Q_{L}$ using Eq. [5]. Next randomness is introduced by making $\delta P_{L}$ a normally distributed random variable with mean value given by the results of Eq. [5] and standard deviation equal to half the mean. 
Table 2. 2020 Economic Parameters

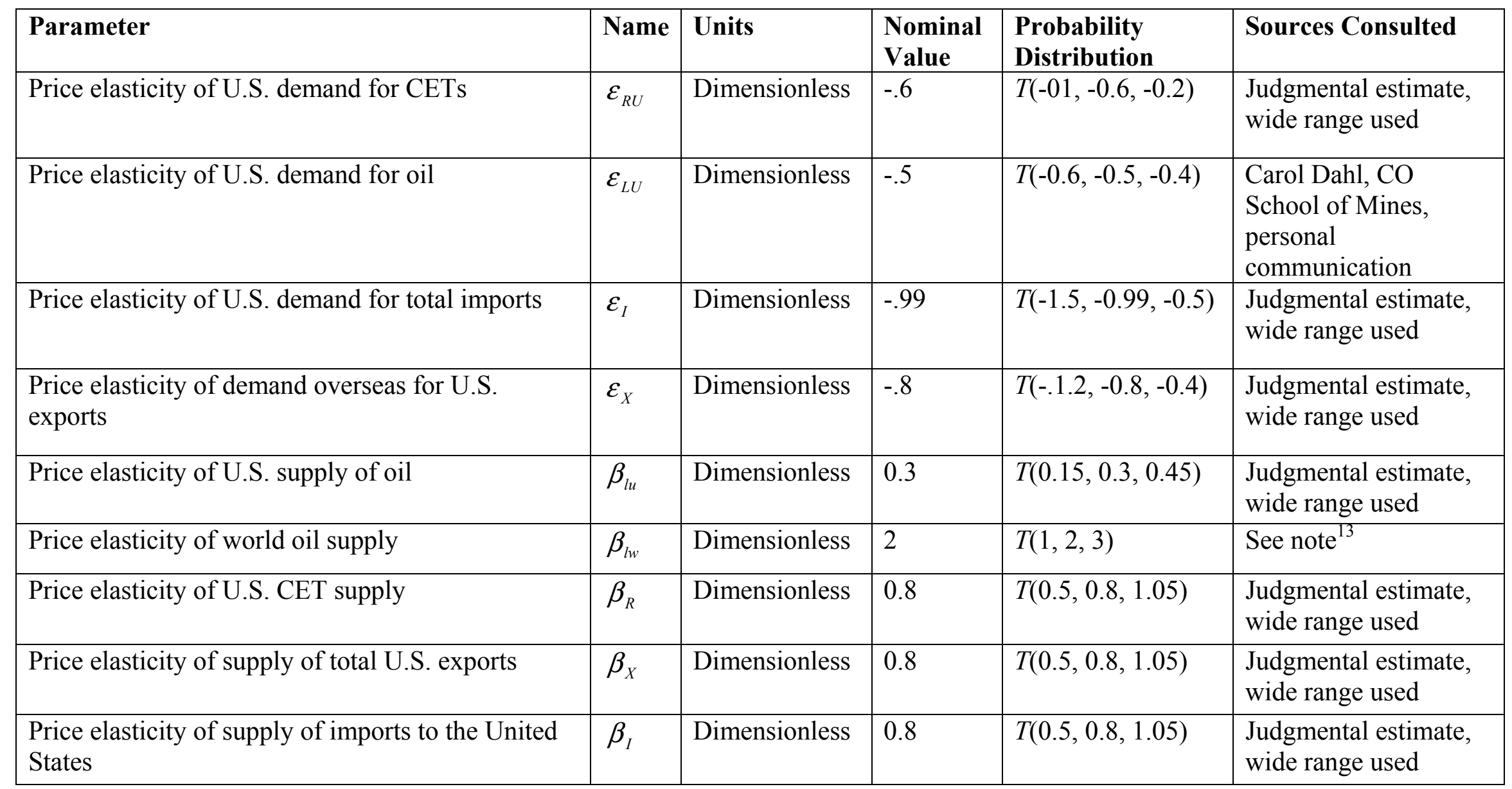

\footnotetext{
${ }^{13}$ This high value for the supply elasticity of world oil was chosen in order to produce a conservative estimate of the potential world oil price effects. The response of world oil prices to exogenous changes in demand is a complex phenomenon that has been the subject of a large literature. We have chosen to use a conservative elasticity to generate the mean of the constant-elasticity representation of Eq. [5] and used a wide range around that mean as described in note Section 2.5 .
} 


\section{Values for 2050}

Table 3. 2050 Scenario Variables

\begin{tabular}{|c|c|c|c|c|c|}
\hline Parameter & Name & Units & $\begin{array}{l}\text { Nominal } \\
\text { Value }\end{array}$ & $\begin{array}{l}\text { Probability } \\
\text { Distribution }\end{array}$ & Sources Consulted \\
\hline Baseline U.S. oil import bill & $\hat{P}_{L} \hat{Q}_{L U}$ & $\begin{array}{l}\text { \$billion per } \\
\text { year }\end{array}$ & 850 & $T(425,850,1275)$ & $\begin{array}{l}\text { EIA }(2008 b) \\
\text { extrapolated }\end{array}$ \\
\hline $\begin{array}{l}\text { Proportional change in U.S. CET } \\
\text { exports }\end{array}$ & $\delta X_{R}$ & Dimensionless & $80 \%$ & $T(20 \%, 80 \%, 140 \%)$ & IEA $(2008)$ \\
\hline Base U.S. expenditures on CET & $\hat{P}_{R} \hat{Q}_{X R}$ & $\begin{array}{l}\text { \$billion per } \\
\text { year }\end{array}$ & 65 & $T(33,65,98)$ & $\begin{array}{l}\text { Judgmental estimate, } \\
\text { wide range used }\end{array}$ \\
\hline $\begin{array}{l}\text { Dollar value of total U.S. trade } \\
\text { (imports }+ \text { exports) }\end{array}$ & $\hat{I}_{T}+\hat{X}_{T}$ & $\begin{array}{l}\text { \$billion per } \\
\text { year }\end{array}$ & 9760 & $T(6830,9760,1270)$ & $\begin{array}{l}\text { EIA (2008a) forecast } \\
\text { of GDP. Current } \\
\text { value for trade as a } \\
\text { fraction of GDP }\end{array}$ \\
\hline $\begin{array}{l}\text { Trade deficit as a fraction of total } \\
\text { trade }\end{array}$ & $D=\frac{\hat{I}_{T}-\hat{X}_{T}}{\hat{I}_{T}+\hat{X}_{T}}$ & Dimensionless & $-10 \%$ & $N(-10 \%, 10 \%)$ & $\begin{array}{l}\text { Assumes gradual } \\
\text { improvement from } \\
\text { current value of } \\
-20 \%\end{array}$ \\
\hline $\begin{array}{l}\text { Value of U.S. imports as a fraction } \\
\text { of global imports }\end{array}$ & $F_{I}$ & Dimensionless & $10 \%$ & $T(7 \%, 10 \%, 13 \%)$ & WTO (2008) \\
\hline $\begin{array}{l}\text { Value of U.S. imports as a fraction } \\
\text { of global imports }\end{array}$ & $F_{X}$ & Dimensionless & $8 \%$ & $T(5.6 \%, 8 \%, 10.4 \%)$ & WTO (2008) \\
\hline
\end{tabular}


Table 4. 2050 Economic Parameters

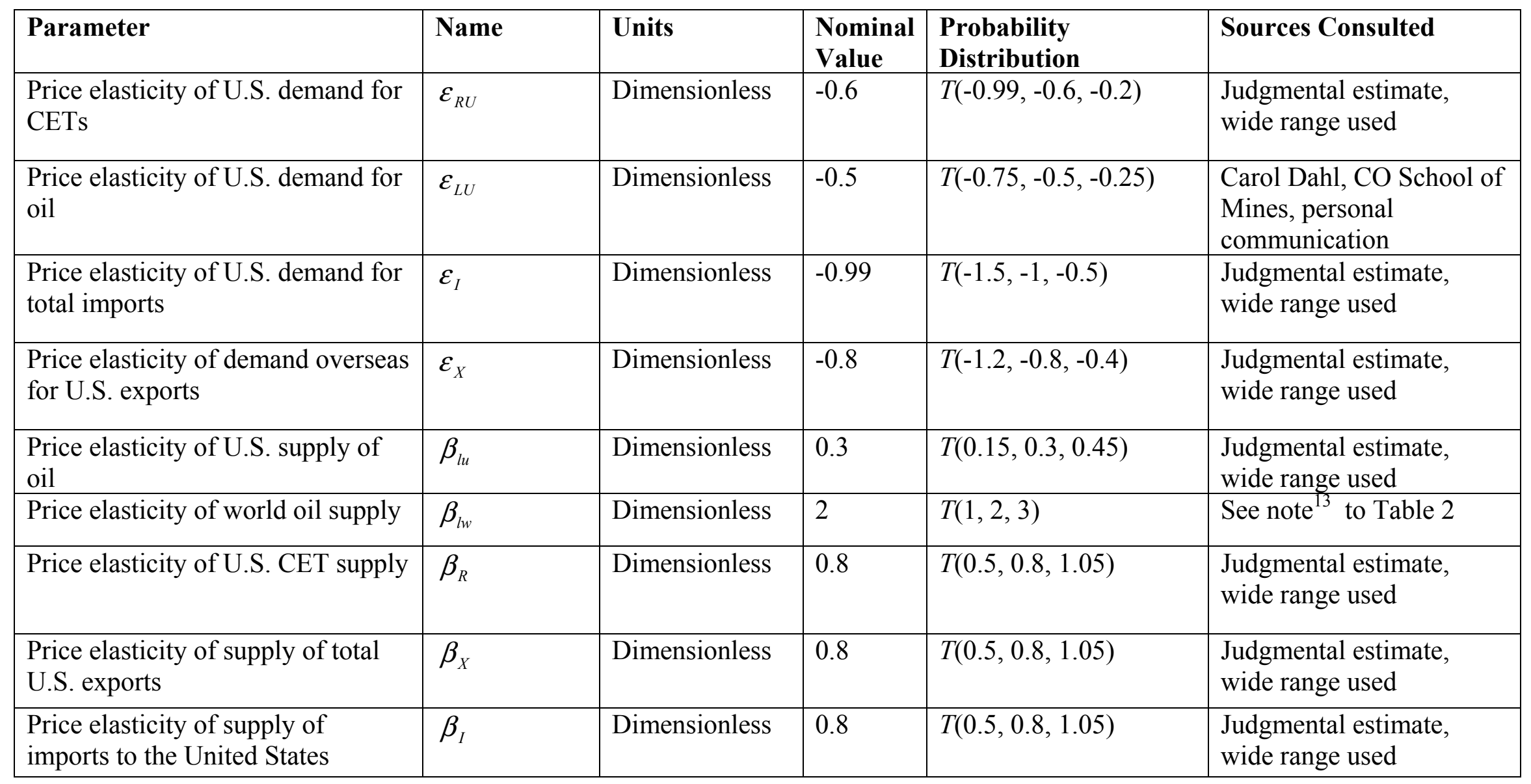




\subsection{Estimating Probability Distributions for Output Variables 2.6.1 Monte Carlo Simulation}

In developing the uncertainty estimates for the benefits estimates, the uncertainty ranges described in Tables1-4 are used as probability distributions. The functions in those tables express estimates of the likelihood that the input parameters lie in a given range.

Given those estimates, the distributions of the output values were calculated by Monte Carlo simulation. The model described in Sections 2.1-2.5 was implemented in an Excel spreadsheet and the Monte Carlo simulation was implemented using the Excel add-in @ Risk 5.5. The resulting distributions for total benefits were shown in Figures 1 and 2.

\subsubsection{Sensitivity Analysis}

The Monte Carlo simulation enables sensitivity analysis that identifies which inputs have the most impact in determining the value of each output variable of interest. Figure 3 illustrates the sensitivity of the total benefits in 2050 to the change in world oil prices. An analysis of the most important determinants of total benefits for 2020 is shown in Table 5.

Table 5 shows the normalized regression coefficients for the output variable representing total benefits in $2020^{14}$. The two strongest determinants of the overall benefits are the change in world oil prices and baseline U.S. oil import cost. Even though the benefits derived from the CET market are a relatively small fraction of the total, the growth in clean energy exports also has a significant impact. The trade surplus, which influences the terms of trade benefit, also has a measurable influence. All the remaining variables are estimated to have normalized impacts of less than $10 \%$ of one standard deviation in the total benefits. For reference, the standard deviation of total benefits in 2020 is about \$24 billion per year.

\footnotetext{
14 The normalized coefficients in Tables 5 and 6 give the regression estimate of the impact on the output variable, measured in standard deviations, induced by a one-standard deviation change in the input variable.
} 
Table 5. Determinants of Total Benefits in 2020

\begin{tabular}{|l|l|l|l|}
\hline Rank & Name & $\begin{array}{l}\text { Regression } \\
\text { Coefficient }\end{array}$ & $\begin{array}{l}\text { Correlation } \\
\text { Coefficient }\end{array}$ \\
\hline 1 & Fractional change in oil price & -0.859 & -0.836 \\
2 & Oil import bill & 0.374 & 0.371 \\
3 & Growth in CET exports & 0.213 & 0.229 \\
4 & Fractional trade surplus & -0.152 & -0.178 \\
5 & Change in CET price & 0.044 & 0.066 \\
6 & Demand elasticity of imports & -0.041 & -0.017 \\
7 & U.S. oil producer revenue & -0.040 & -0.014 \\
8 & Supply elasticity of CET exports & -0.020 & -0.052 \\
\hline
\end{tabular}

Table 6 presents the corresponding analysis of total benefits in 2050 .

Table 6. Determinants of Total Benefits in 2050

\begin{tabular}{|l|l|l|l|}
\hline Rank & Name & $\begin{array}{l}\text { Regression } \\
\text { Coefficient }\end{array}$ & $\begin{array}{l}\text { Correlation } \\
\text { Coefficient }\end{array}$ \\
\hline 1 & Fractional change in oil price & -0.855 & -0.887 \\
2 & Oil import bill & 0.291 & 0.308 \\
3 & Fractional trade surplus & -0.186 & -0.218 \\
4 & U.S. oil producer revenue & 0.120 & 0.151 \\
5 & Change in CET price & 0.054 & 0.074 \\
6 & Demand elasticity of imports & -0.054 & -0.055 \\
7 & Growth in CET exports & 0.048 & 0.041 \\
\hline
\end{tabular}

The two most important determinants of total benefits in 2050 are the same as for those in 2020: change in oil price and baseline oil import bill. Next in importance are the balance of trade, baseline revenue for U.S. CET producers, change in CET price, and elasticity of demand for imports. Other input variables have less than 5\% impact in terms of standard deviations of total benefits. (The standard deviation of total benefits in 2050 is $\$ 150$ billion per year.) 


\subsection{Conclusions}

The framework described above can be used to estimate the economic benefits to the United States of coordinated global action to increase the uptake of CETs worldwide. Together with a Monte Carlo simulation engine, the framework can be used to develop plausible ranges for benefits, taking into account the large uncertainty in the driving variables and economic parameters. The resulting estimates illustrate that larger global clean energy markets offer significant opportunities to the U.S. economy.

This analysis also leaves several important questions unanswered. Some of the technical ones have been mentioned in Section 2.2. More importantly, this analysis does not address the determinants of whether and how U.S. businesses can capture a significant share of growing global clean energy markets. Further work in that area would refine our understanding of the plausible range of future U.S. clean energy exports; the estimate provided here could be considered conservative. A better understanding of the dynamics of those markets will also inform U.S. strategy for maintaining and enhancing its competitiveness in this increasingly important global sector. 


\section{References}

Dahl, C. (June, 2008). Personal E-mail. Colorado School of Mines, Golden, CO.

Energy Information Administration (EIA). (2008a). "International Energy Outlook 2008.” U.S. Energy Information Administration. http://www.eia.doe.gov/oiaf/ieo/. Accessed June 2008.

EIA. (2008b). "Annual Energy Outlook 2008.” U.S. Energy Information Administration. http://www.eia.doe.gov/oiaf/aeo/. Accessed June 2008.

International Energy Agency (IEA). (2008). Energy Technology Perspectives. Presented at a 2008 G8 Summit in Hokkaido/Toyako (Japan). July 2008.

http://www.iea.org/Textbase/techno/etp/ETP_2008.pdf. Accessed June 2010.

National Renewable Energy Laboratory (NREL), and World Resources Institute, in cooperation with the Center for Strategic and International Studies. (2008).

Strengthening U.S. Leadership of International Clean Energy Cooperation: Proceedings of Stakeholder Consultations. NREL/TP-6A0-44261. Golden, CO: National Renewable Energy Laboratory.

U.S. International Trade Commission (USITC). (October 2005). Renewable Energy Services: An Examination of U.S. and Foreign Markets. "Investigation No. 332-462, USITC Publication 3805, USITC, Washington D.C.

World Trade Organization (WTO). 2008. "Statistics Database: United States.”U.S. http://stat.wto.org/CountryProfile/WSDBCountryPFView.aspx? Language=E\&Country= US. Accessed March 27, 2010. 


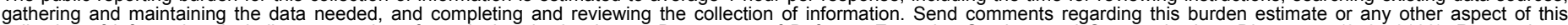

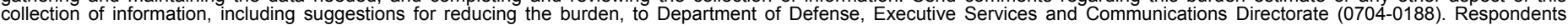

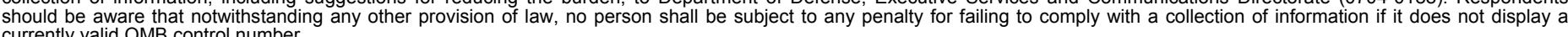

PLEASE DO NOT RETURN YOUR FORM TO THE ABOVE ORGANIZATION.
1. REPORT DATE (DD-MM-YYYY) July 2010
4. TITLE AND SUBTITLE
Benefits to the United States of Increasing Global Uptake of Clean Energy Technologies

3. DATES COVERED (From - To)

5a. CONTRACT NUMBER

DE-AC36-08-GO28308

5b. GRANT NUMBER

5c. PROGRAM ELEMENT NUMBER

5d. PROJECT NUMBER

NREL/TP-6A2-47807

5e. TASK NUMBER

DOCC. 1002

5f. WORK UNIT NUMBER
7. PERFORMING ORGANIZATION NAME(S) AND ADDRESS(ES)

National Renewable Energy Laboratory

1617 Cole Blvd.

Golden, CO 80401-3393

9. SPONSORING/MONITORING AGENCY NAME(S) AND ADDRESS(ES)

\section{PERFORMING ORGANIZATION REPORT NUMBER \\ NREL/TP-6A2-47807}

10. SPONSOR/MONITOR'S ACRONYM(S) NREL

11. SPONSORING/MONITORING AGENCY REPORT NUMBER

\section{DISTRIBUTION AVAILABILITY STATEMENT}

National Technical Information Service

U.S. Department of Commerce

5285 Port Royal Road

Springfield, VA 22161

\section{SUPPLEMENTARY NOTES}

\section{ABSTRACT (Maximum 200 Words)}

A previous report describes an opportunity for the United States to take leadership in efforts to transform the global energy system toward clean energy technologies (CET). An accompanying analysis to that report provides estimates of the economic benefits to the United States of such a global transformation on the order of several hundred billion dollars per year by 2050 . This report describes the methods and assumptions used in developing those benefit estimates. It begins with a summary of the results of the analysis based on an updated and refined model completed since the publication of the previous report. The framework described can be used to estimate the economic benefits to the U.S. of coordinated global action to increase the uptake of CETs worldwide. Together with a Monte Carlo simulation engine, the framework can be used to develop plausible ranges for benefits, taking into account the large uncertainty in the driving variables and economic parameters. The resulting estimates illustrate that larger global clean energy markets offer significant opportunities to the United States economy.

\section{SUBJECT TERMS}

energy policy; clean energy technology; CET; greenhouse gas; GHG; oil; Monte Carlo simulation; global; international; market

\begin{tabular}{|c|c|c|c|c|}
\hline \multicolumn{3}{|c|}{ 16. SECURITY CLASSIFICATION OF: } & \multirow{2}{*}{$\begin{array}{l}\text { 17. LIMITATION } \\
\text { OF ABSTRACT } \\
\text { UL }\end{array}$} & \multirow{2}{*}{$\begin{array}{ll}\text { 18. } & \text { NUMBER } \\
\text { OF PAGES }\end{array}$} \\
\hline $\begin{array}{l}\text { a. REPORT } \\
\text { Unclassified }\end{array}$ & $\begin{array}{l}\text { b. ABSTRACT } \\
\text { Unclassified }\end{array}$ & $\begin{array}{l}\text { c. THIS PAGE } \\
\text { Unclassified }\end{array}$ & & \\
\hline
\end{tabular}

19a. NAME OF RESPONSIBLE PERSON

19b. TELEPHONE NUMBER (Include area code) 